\title{
Efficiency and cell viability implications using tip type electroporation in zebrafish sperm cells
}

\author{
Larissa O. Daneluz ${ }^{1}$ Izani B. Acosta ${ }^{2,3}$ - Leandro S. Nunes ${ }^{1}$. Eduardo B. Blodorn ${ }^{1} \cdot$ William B. Domingues $^{1}$. \\ Amanda W. S. Martins ${ }^{1}$ • Eduardo N. Dellagostin ${ }^{1}$. Gabriela T. Rassier ${ }^{1}$. Carine D. Corcini ${ }^{2}$. Charles N. Fróes ${ }^{4}$. \\ Eliza R. Komninou ${ }^{1,2} \cdot$ Antônio S. Varela Jr ${ }^{2,3}$. Vinicius F. Campos ${ }^{1}$ (i)
}

Received: 7 March 2020 / Accepted: 8 July 2020 / Published online: 13 July 2020

(c) Springer Nature B.V. 2020

\begin{abstract}
Sperm-mediated gene transfer (SMGT) has a potential use for zebrafish transgenesis. However, transfection into fish sperm cells still needs to be improved. The objective was to demonstrate the feasibility of tip type electroporation in zebrafish sperm, showing a protocol that provide high transfection efficiency, with minimal side-effects. Sperm was transfected with a Cy3-labelled DNA using tip type electroporation with voltages ranging from 500 to $1500 \mathrm{~V}$. Sperm kinetics parameters were assessed using Computer Assisted Semen Analysis (CASA) and cell integrity, reactive oxygen species (ROS), mitochondrial functionality and transfection rate were evaluated by flow cytometry. The transfection rates were positively affected by tip type electroporation, reaching $64.9 \% \pm 3.6$ in the lowest voltage used $(500 \mathrm{~V})$ and $86.6 \% \pm 1.9$ in the highest $(1500 \mathrm{~V})$. The percentage of overall motile sperm in the electrotransfected samples was found to decrease with increasing field strength $(P<0.05)$. Increase in the sperm damaged plasma membrane was observed with increasing field strength $(P<0.05)$. ROS and sperm mitochondrial functionality did not present a negative response after the electroporation $(P>0.05)$. Overall results indicate that tip type electroporation enhances the internalization of exogenous DNA into zebrafish sperm cells with minimal harmful effects to sperm cells.
\end{abstract}

Keywords Danio rerio $\cdot$ Electroporation $\cdot$ Spermatozoa $\cdot$ Exogenous DNA $\cdot$ SMGT

Electronic supplementary material The online version of this article (https://doi.org/10.1007/s11033-020-05658-2) contains supplementary material, which is available to authorized users.

Vinicius F. Campos

fariascampos@gmail.com

1 Laboratório de Genômica Estrutural, Programa de Pós-Graduação em Biotecnologia, Centro de Desenvolvimento Tecnológico, Universidade Federal de Pelotas, Pelotas, RS, Brazil

2 ReproPel, Programa de Pós-Graduação em Veterinária, Faculdade de Veterinária, Universidade Federal de Pelotas, Pelotas, RS, Brazil

3 Laboratório de Reprodução Animal, Programa de Pós-Graduação em Biologia de Ambientes Aquáticos Continentais, Instituto de Ciências Biológicas - Universidade Federal do Rio Grande, Rio Grande, RS, Brazil

4 Laboratório de Ictiologia, Faculdade de Zootecnia - Universidade Federal de Pelotas, Pelotas, RS, Brazil

\section{Introduction}

Transfection of foreign genes has been explored to generate genetically modified animals by sperm-mediated gene transfer (SMGT) [1]. This technique is based on the ability of sperm cells to spontaneously bind exogenous DNA and transport it into an oocyte during fertilization [2]. However, this technique also suffers from a several drawbacks, being the most challenging the DNA bind and subsequently uptake by sperm cells. As sperm cells are considered hardto-transfect cells, a series of studies has tried to enhance its DNA uptake [3, 4]. Besides, these studies produced different results, some actually produced transgenic animals [5] and others could not effectively generate transgenic animals [6]. These results varying according to species and the work contexts.

Classical electroporation is a non-viral electrotransfection method for DNA delivery into cells or tissues without the use of additional chemicals or viruses [7] and a fast and inexpensive approach to transfect sperm cells [8]. Despite 
increased DNA uptake by sperm cells, some problems are associated with the conventional cuvette type electroporation, such as low transfection rate, mosaic gene expression, and negative effects on cell viability [9]. Capillary electroporation (tip-type electroporation) was first described in 2008 [10] and since that, it has been consolidated as a new electrotransfection method capable to provide high transfection efficiency on a wide range of mammalian cells with high survival rates of treated cells $[10,11]$. The mechanical design of tip type electroporation leads to rapid cell delivery by pipette, improving the electroporation efficiency. In addition, the design of pipette tips containing gold electrodes produced a very small electroporation reaction with more uniform electric field [10]. In this configuration, the negative effects of the conventional electroporation system, such as change in $\mathrm{pH}$ and generation of metal ions, harmful to the cells, are quite reduced, leading to a safer and more efficient transfection. Recently, we successful demonstrated the electrotransfection in cryopreserved bovine spermatozoa through a new protocol using the tip type electroporation [11]. However, no other studies using tip type electroporation for sperm cells have been conducted. Electroporation could be affected by several factors, on this way, the optimal conditions for tip type electroporation for each cell type must be experimentally determined [10]. In addition, interspecies and intra-species lead to a variability in transfection rate being an unsolved problem associated with electroporation [12]. Since 1999 electroporation based on cuvette chambers has been used to transform fish sperm cells [13, 14]. However, few data are available about the transfection rate for fish spermatozoa. Most studies only investigate the gene transfer efficiency, being found to be between 20-30\% using conventional electroporation [12], without evaluating the transfection rate in fish sperm. Some studies have investigated the negative effects of seminal plasma DNase on sperm DNA uptake, however, no reliable data are available for optimization of electroporation for fish spermatozoa $[15,16]$.

Zebrafish is the most popular fish species for laboratory research being the transgenic zebrafish an experimental model for several studies in field of biomedical research, developmental biology and drug testing [17]. Zebrafish is also being considered as a possible animal model to study COVID-19 [18]. Nevertheless, laborious microinjection is still the standard method to generate transgenic zebrafish [15]. Until now, few studies been performed for zebrafish transgenesis using SMGT with controversial results [9, 13, 19]. Recently, different studies demonstrated that SMGT could be associated to genome editing tools such as CRISPR-Cas technology, increasing its potential use in the genome editing era to generate transgenic zebrafish [20-22].

The objective of this study was to demonstrate the feasibility of tip type electroporation in Danio rerio sperm, allowing its further use in SMGT, showing a protocol that provide high transfection efficiency, with minimal sideeffects on sperm cells.

\section{Materials and methods}

\section{Animals and semen collection}

Management and maintenance of zebrafish were in compliance with the Zebrafish Book (www.zfin.org). Fish were obtained in a commercial establishment and kept in a closed culture system containing dechlorinated, nitrite free and aerated water at $28 \pm 2{ }^{\circ} \mathrm{C}, \mathrm{pH} 7.0$, under photoperiod of $12 \mathrm{~h}$ light: $12 \mathrm{~h}$ dark. The animals were fed ad libitum with commercial fish feed, twice daily (Tetra ColorBits). For each replicate of the experiment, 4 males with 4-6 months of age were sacrificed by sectioning the spinal cord (the accepted method when the use of anaesthesia can affect the results of sperm analysis) [23]. Through an abdominal incision and dissection, the gonads were removed and placed in a microtube containing $200 \mu \mathrm{L}$ of Beltsville Thawing SolutionBTS at $4{ }^{\circ} \mathrm{C}$ with pH 7.4 and an osmolality of $350 \mathrm{mOsm}$ [24] obtaining a sperm pool from the different males. The experiment was performed in 3 replicates $(n=12)$. This study was conducted in compliance with institutional, national, or international guidelines for using animals and was approved by the Ethics Committee of the Federal University of Pelotas / RS, Brazil, (number 7836).

\section{Preparation of Cy-3 labelled DNA}

As a marker to identify the sperm that incorporate exogenous DNA, a fluorescent-conjugated DNA was prepared by amplifying a $546 \mathrm{bp}$ fragment of the pEGFP-N1 vector (Clontech Laboratories, Basingstoke, UK) with Cy-3-labelled primers as previously described by our group [25]. Briefly, PCR was performed using 35 cycles at $94{ }^{\circ} \mathrm{C}$ for $30 \mathrm{~s}, 62{ }^{\circ} \mathrm{C}$ for $30 \mathrm{~s}$, and $72{ }^{\circ} \mathrm{C}$ for $30 \mathrm{~s}$. A single band was confirmed by gel electrophoresis. The concentration and purity were determined by UV spectrophotometer (NanoVue Plus, GE Healthcare Life Sciences, NJ, USA). The Cy3-labelled primers sequences were the following: 5'-ACG TAAACGGCCACAAGTTC and 5'-AGTCGTGCTGCTTCA TGTG $[25,26]$.

\section{Sperm preparation, DNA electrotransfection and experimental design}

Sperm concentration was assessed from the pool of samples through sperm counting in a Neubauer chamber. For all transfection procedures exogenous DNA consisted of a $546 \mathrm{bp}$ fragment labelled with $\mathrm{Cy}-3$ prepared as described 
above. Transfection was performed using $1 \times 10^{6}$ sperm cells mixed with $1 \mu \mathrm{g}$ of a Cy3-labelled DNA were diluted in BTS in a final volume of $10 \mu \mathrm{L}$. Tip type electroporation was conducted using the Neon ${ }^{\circledR}$ Transfection System (Invitrogen, Carlsbad, CA, USA). The experiments consisted of five electroporated groups at different voltages $(500,750,1000$, 1250 and $1500 \mathrm{~V}$ ). Non-electroporated sperm cells (with and without DNA) were used as controls. Electroporation was carried out with different voltages as mentioned above, but always the same number of pulses (1 pulse), time constant $(1 \mathrm{~ms})$ and volume of the electroporated sample $(10 \mu \mathrm{L})$. To separate sperm from DNA which has not internalized to the sperm membrane, sperms were centrifuged ( $5 \mathrm{~min}$ at $700 \times g$ ) and washed three times using BTS medium, followed by incubation with $1 \mathrm{U}$ of DNase I (Invitrogen) for 60 min $[9,19,25,27]$. All samples from all groups were treated with DNase I. After DNase treatment, sperm cells were washed three times with BTS medium by centrifuging samples at $700 \times g$ for $5 \mathrm{~min}$ [25]. After this transfection procedure, the samples were evaluated by CASA to determine cinematic parameters and flow cytometry to determine cell integrity, reactive oxygen species (ROS), mitochondrial functionality and transfection rate. This experiment was replicated three times.

\section{Assessment of sperm kinetics parameters using Computer Assisted Semen Analysis (CASA)}

To determine kinetics parameters, $1 \mu \mathrm{L}$ of semen sample and $4 \mu \mathrm{L}$ of fresh water were placed on slides under coverslips and analysed using Computer-Assisted Sperm Analyses (CASA) system (AndroVision 3.5, Minitube, Germany) combined with an Axio Scope.A1® optical microscope (Zeiss, Germany). CASA software setup was adjusted according to Wilson-Leedy and Ingermann [28]. The evaluations were performed after 5 independent sperm activations in at least 500 cells for group, and for no more than $10 \mathrm{~s}$ after starting the sperm movement. Total motility (\%), progressive motility (\%), curvilinear velocity (VCL), straight-line velocity (VSL), average path velocity (VAP), and straightness (STR) were accessed.

\section{Motility duration analysis}

The duration of motility was determined based on the time recorded between activation and complete arrest of sperm progressive movement. For the activation of the spermatozoa, $1 \mu \mathrm{L}$ of semen sample and $4 \mu \mathrm{L}$ of fresh water were placed on slides under coverslips at room temperature, following the method described by Collares and collaborators [29].

\section{Flow cytometry analysis}

Cell integrity, membrane fluidity, mitochondrial functionality, concentration of reactive oxygen species (ROS) and total of sperm-bound exogenous DNA were evaluated by flow cytometry (Attune ${ }^{\circledR}$ Acoustic Focusing Cytometer, Applied Biosystems, USA) as previously described [30]. To detect the sperm population, non-sperm events were eliminated from the analysis by scatter plots of FSC $\times$ SSC $[31,32]$ and debris were eliminated by staining cells with Hoechst 33342 at a concentration of $16.2 \mathrm{M}$ (Sigma-Aldrich Co., St. Louis, MO, USA). A total of 10,000 events per sperm sample with a flow of 200 cells/s were analysed using the Cytometric Attune Software V2.1 program.

To verify the integrity of the plasma membrane (cell integrity), we used $20 \mathrm{M}$ Carboxyfluorescein diacetate (CDFA) and $7.3 \mu \mathrm{M}$ Propidium Iodide (PI) (Sigma-Aldrich Co., St. Louis, MO, USA). Cells with intact membranes were differentiated from permeable cells by their ability to exclude propidium iodide (PI) that easily penetrate dead or damaged cells. The sperm were classified as intact (CDFA +/PI-) and permeable (CDFA +/PI + ; CDFA -/ $\mathrm{PI}+$; CDFA -/PI-) [11]. The rate was calculated from the number of not-damaged sperm cells with functional membrane/number of sperm cells positive for $\mathrm{H} 33342$, this number was multiplied by 100 to express the percentage of spermatozoa for each category and the result were expressed as percentage of cells with intact membranes.

To determine the concentration of reactive oxygen species (ROS) concentration was determined using final concentrations of $1.0 \mu \mathrm{M}$ and $7.3 \mu \mathrm{M}$ for fluorescent dye 2'7-dichlorofluorescein diacetate (DCF) and PI (Sigma-Aldrich Co., St. Louis, MO, USA), respectively. The results were expressed in fluorescence intensity measured in arbitrary units, considering only the mean intensity of green fluorescence in living sperm (PI) [33].

Sperm membrane fluidity was analysed using hydrophobic Merocyanine-540 dye (M540) (Sigma-Aldrich Co., St. Louis, MO, USA) at a final concentration of $2.7 \mu \mathrm{M}$ and YO-PRO1 marker (Invitrogen, Eugene, USA) at a final concentration of $0.1 \mu \mathrm{M}$. Only live sperm (YO-PRO negative) were selected and classified with high or low fluidity depending on the intensity of M540 orange fluorescence [34]. Data were expressed as the percentage of spermatozoa with higher membrane fluidity.

Mitochondrial function was assessed using the Rhodamine 123 marker (Sigma-Aldrich Co., St. Louis, MO, USA) at a final concentration of $100 \mathrm{nM}$ combined with PI $(7.5 \mu \mathrm{M})$. High or low mitochondrial function were determined depending on the intensity of Rhodamine green fluorescence [35]. Cells stained with PI were excluded from mitochondrial function analysis. The results were 
expressed as the percentage of sperm cells with functional mitochondria.

The transfection rate of sperm cells after tip type electroporation was obtained by flow cytometry as previously described [25]. The efficiency of this technique was previously evaluated by confocal microscopy by Domingues et al. [25]. The intensity of orange (Cy-3-labelled exogenous DNA) and blue fluorescence (H33342) was recorded using band pass filters. The percentage of the transfected sperm was determined by the proportion of the cells emitting orange (Cy-3-labelled DNA) fluorescence out of the total number of the cells analysed.

\section{Statistical analysis}

The normality distribution of data was evaluated by the Shapiro-Wilk test. Differences between groups on cinematic sperm parameters and flow cytometry data were analysed by Two-way ANOVA followed by Tukey's post hoc test. Transfection rate was compared by One-Way ANOVA followed by Tukey's post hoc test. A $P<0.05$ was defined as statistical significance.

\section{Results}

\section{Effect of the DNA electrotransfection on sperm motion and velocity parameters}

Electroporation did not activate the sperm, since in all the groups motility was initiated only after the contact with the fresh water.

The percentage of overall motile sperm in the electrotransfected samples was found to decrease with increasing field strength $(P<0.05)$ when compared to the control (nonelectroporated cells), as demonstrated in Fig. 1a. In addition, the presence of exogenous DNA in the electroporation process did not interfere on the total motility and progressive motility $(P>0.05)$.

The reduction in overall motile sperm was less pronounced at the lowest tested voltages $(500$, and $750 \mathrm{~V})$. Total motility in these groups were $64.8 \% \pm 1.6$ and $62.7 \% \pm 1.9$ when electroporated without exogenous DNA, and $63.6 \% \pm 1.8$ and $61.6 \% \pm 1.6$ when electroporated with exogenous DNA, respectively. Higher voltages, such as $1250 \mathrm{~V}$ and $1500 \mathrm{~V}$, reduced cell motility to approximately $53.6 \% \pm 1.6$ and $52.7 \% \pm 1.7$, respectively $(P<0.05)$, when electroporated without DNA.

The progressive motility of spermatozoa electroporated with $500 \mathrm{~V}$ and $750 \mathrm{~V}$ was not different when compared to the electroporated control with DNA $(P>0.05)$, as demonstrated in Fig. 1b. Progressive motility in these groups were $59.4 \% \pm 1.6$ and $55.7 \% \pm 1.9$ when electroporated without


Fig. 1 Sperm motility parameters in Zebrafish Danio rerio electroporated (with or without exogenous DNA). Data are expressed as mean \pm SEM $(\mathrm{N}=3)$. Control black bar (without exogenous DNA and not electroporated). Control gray bar (not electroporated) was transfected without electroporation. a Evaluation of Sperm motility by CASA (percentage of motile cells). b Evaluation of Progressive motility (percentage of cells with progressive motility). c Evaluation of Sperm motility duration (time of motility duration measured in seconds). Uppercase was used to demonstrate differences within voltages $(P<0.05)$. Lowercase was used to demonstrate differences within groups treated with or without exogenous DNA $(P<0.05)$ 
DNA, and $56.6 \% \pm 1.8$ and $54.8 \% \pm 1.6$ when electroporated with DNA, respectively. Higher voltages also showed decreased $(P<0.05)$ progressive motility when compared to the control and to other experimental groups (Supplementary Table S1).

No significant differences were observed for curvilinear velocity (VCL) between tested voltages and control groups $(P>0.05$, Table 1). However, higher voltages showed decreased $(P<0.05)$ straight-line velocity $(\mathrm{VSL})$ and straightness (STR), when compared to other experimental groups including the control. The electroporated groups with $500 \mathrm{~V}$ and $750 \mathrm{~V}$, in the presence of exogenous DNA, presented average path velocity (VAP) similar to non-electroporated control group $(P>0.05)$.

Electroporation with the highest voltages (1250 and $1500 \mathrm{~V})$ significantly reduced $(P<0.05)$ sperm movement duration, when compared to the control group without exogenous DNA (Fig. 1c). However, in the group incubated with DNA without electroporation the sperm motility right after the initiation, decreased more drastically with elapsing time when compared with the others experimental groups $(P<0.05)$.

\section{Effect of DNA electrotransfection on cell integrity, ROS production and sperm mitochondrial functionality}

An increase in the sperm damaged plasma membrane was observed with increasing field strength $(P<0.05)$ (Fig. 2a). On the other hand, ROS and sperm mitochondrial functionality did not present a negative response after the electroporation $(P>0.05)$ among the different voltages, as demonstrated in Fig. 2b, c.

\section{Assessment of transfection rate}

All electroporated groups demonstrated significant higher transfection rates when compared to the control group $(P<0.05)$. The sperm autofluorescence showed a slight emission demonstrating that the fluorescence observed in the other groups belongs to exogenous DNA (Fig. 3). The transfection rate in control without electroporation was $39.4 \% \pm 1.6$. Tip type electroporation using voltages of 500, 750, 1000 and 1250 increased the transfection rate in comparison to control without electroporation $(P<0.05)$, however they did not differ among them $(P>0.05$, Fig. 3$)$. The highest voltage $(1500 \mathrm{~V})$ differ only from the controls and the $750 \mathrm{~V}$ group $(P<0.05)$ reaching to $86.6 \% \pm 1.9$ of sperm cells carrying exogenous DNA.

\section{Discussion}

In this study, capillary and wire-type electroporation was used for gene transfer in zebrafish sperm. Here we look forward to improving the electroporation technique in zebrafish sperm based on capillary tip type electroporation [10]. Overall results indicate that tip type electroporation enhances the internalization of exogenous DNA into zebrafish sperm cells. We found a transfection rate around to $40 \%$ without electroporation (control) and when tip type electroporation was performed, we reach to $86 \%$ at highest voltage used. Transfection level found in control without electroporation
Table 1 Values for velocity parameters measured by computer-assisted semen analysis

\begin{tabular}{llllll}
\hline & Exogenous & VCL $(\mu \mathrm{m} / \mathrm{s})$ & VAP $(\mu \mathrm{m} / \mathrm{s})$ & VSL $(\mu \mathrm{m} / \mathrm{s})$ & STR $(\%)$ \\
& DNA & & & & \\
\hline $\begin{array}{c}\text { Non- elec- } \\
\text { troporated }\end{array}$ & - & $99.6 \pm 6.1$ & $91.7 \pm 2.2^{\mathrm{A}}$ & $88.8 \pm 2.2^{\mathrm{A}}$ & $0.93 \pm 0.06^{\mathrm{A}}$ \\
$500 \mathrm{~V}$ & - & $89.5 \pm 6.3$ & $84.3 \pm 2.2^{\mathrm{A}}$ & $79.4 \pm 2.2^{\mathrm{A}}$ & $0.93 \pm 0.06^{\mathrm{A}}$ \\
& + & $92.5 \pm 7.2$ & $84.5 \pm 2.6^{\mathrm{A}}$ & $74.3 \pm 2.6^{\mathrm{A}, \mathrm{B}}$ & $0.92 \pm 0.07^{\mathrm{A}}$ \\
$750 \mathrm{~V}$ & - & $92.5 \pm 7.8$ & $85.5 \pm 2.8^{\mathrm{A}}$ & $80.1 \pm 2.8^{\mathrm{A}, \mathrm{B}}$ & $0.93 \pm 0.08^{\mathrm{A}}$ \\
& + & $93.6 \pm 8.8$ & $84.1 \pm 3.2^{\mathrm{A}}$ & $79.6 \pm 3.2^{\mathrm{A}, \mathrm{B}}$ & $0.92 \pm 0.09^{\mathrm{A}, \mathrm{B}}$ \\
$1000 \mathrm{~V}$ & - & $100.4 \pm 6.9$ & $75.7 \pm 2.5^{\mathrm{B}}$ & $71.8 \pm 2.5^{\mathrm{B}}$ & $0.91 \pm 0.07^{\mathrm{B}}$ \\
& + & $88.0 \pm 5.8$ & $75.4 \pm 2.1^{\mathrm{B}}$ & $73.6 \pm 2.1^{\mathrm{B}}$ & $0.90 \pm 0.06^{\mathrm{B}}$ \\
$1250 \mathrm{~V}$ & - & $85.3 \pm 7.2$ & $71.7 \pm 2.6^{\mathrm{B}}$ & $72.4 \pm 2.6^{\mathrm{B}}$ & $0.90 \pm 0.07^{\mathrm{B}}$ \\
& + & $81.0 \pm 7.3$ & $74.9 \pm 2.6^{\mathrm{B}}$ & $69.4 \pm 2.6^{\mathrm{B}}$ & $0.90 \pm 0.07^{\mathrm{B}}$ \\
$1500 \mathrm{~V}$ & - & $86.1 \pm 7.4$ & $75.3 \pm 2.7^{\mathrm{B}}$ & $74.3 \pm 2.7^{\mathrm{B}}$ & $0.88 \pm 0.08^{\mathrm{C}}$ \\
& + & $85.5 \pm 7.6$ & $73.5 \pm 2.7^{\mathrm{B}}$ & $74.4 \pm 2.7^{\mathrm{B}}$ & $0.87 \pm 0.07^{\mathrm{C}}$ \\
\hline
\end{tabular}

The absence or presence of exogenous DNA is represented by -and +, respectively. Sperm motion parameters from zebrafish spermatozoa presented above: VCL curvilinear velocity, VAP average path velocity, VSL straight-line velocity, STR straightness. 4 different males were used to obtain a pool of semen; each treatment was repeated three times using different pool samples $(\mathrm{N}=3)$. Data are expressed as mean \pm SEM. Numbers within columns with different superscripts (A, B and C) are statistically different $(P<0.05)$ 

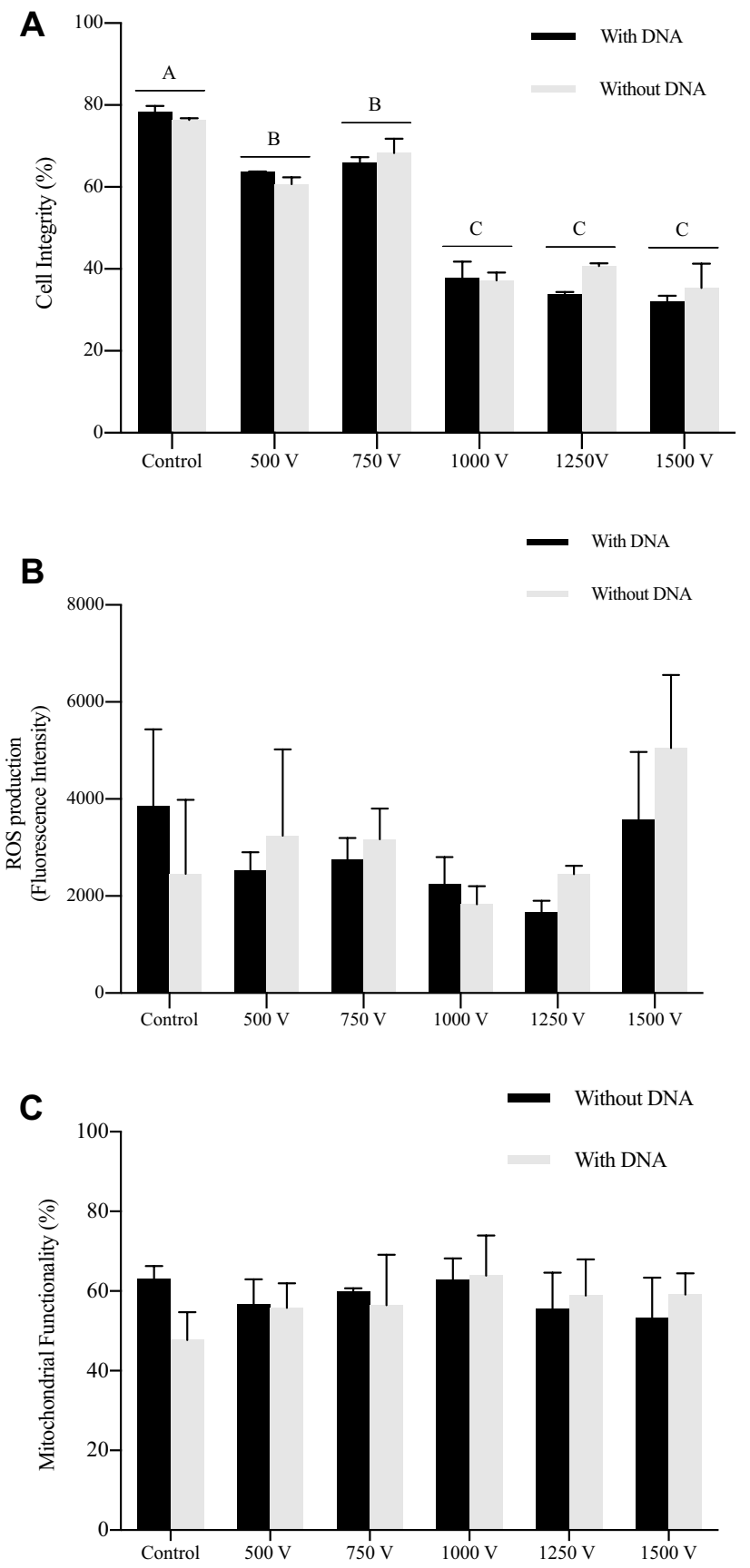

Fig. 2 Quality parameters evaluated by flow cytometry of spermatozoa from Zebrafish Danio rerio electroporated (with and without DNA). Data are expressed as mean $\pm \operatorname{SEM}(\mathrm{N}=3)$. Control black bar (without exogenous DNA and not electroporated). Control gray bar (not electroporated) was transfected without electroporation. a Evaluation of ROS production by flow cytometry (fluorescence intensity measured in arbitrary units). b Evaluation of cell integrity by flow cytometry (percentage of cells with intact membrane). Uppercase was used to demonstrate differences within voltages $(P<0.05)$. c Evaluation of sperm mitochondrial functionality by flow cytometry (percentage of sperm cells with functional mitochondria).

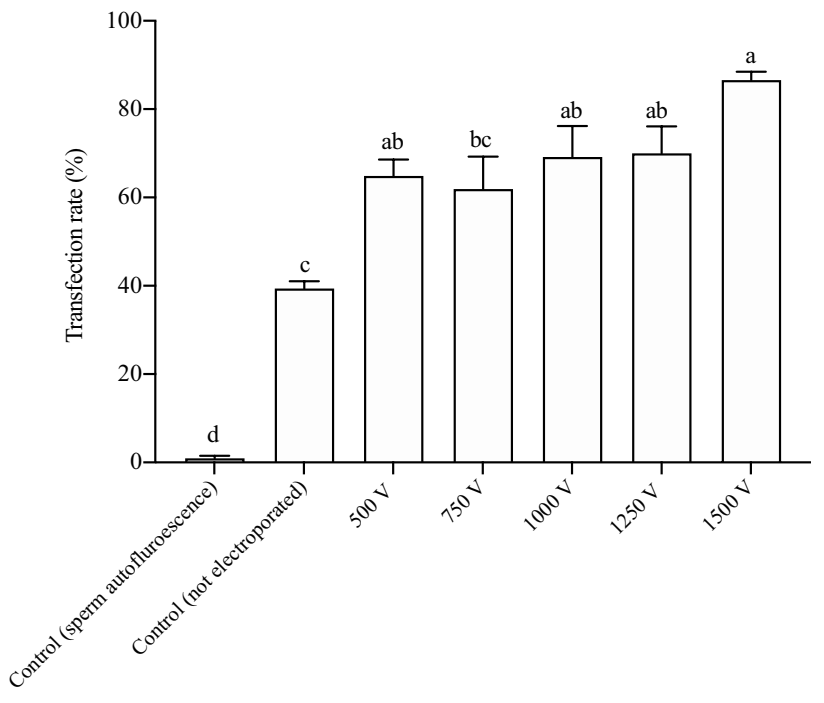

Fig. 3 Transfection rates of zebrafish sperm cells. Percentage of cells transfected with Cy3-labelled DNA after tip type electroporation. Control of sperm autofluorescence (without exogenous DNA and not electroporated). Control (not electroporated) was transfected without electroporation. a,b,c,d Different letters among treatments indicate significant differences $(P<0.05)$, respectively. ANOVA was used for analysis. Data are expressed as mean $\pm \operatorname{SEM}(\mathrm{N}=3)$

corroborates with other previous studies. The fragment used in our study had $546 \mathrm{bp}$. We previously observed the transfection rate of $45 \%$ for cryopreserved bovine sperm on control without electroporation and using this same fragment [25]. In addition, our data are in agreement with previous studies showing that $45 \%$ of bovine sperm cells spontaneous uptake exogenous DNA, even being it an entire plasmid [36]. Lavitrano et al. shows that sperm cells take up more efficiently larger DNA molecules $(7 \mathrm{~kb})$ as compared with the smallest (150-750 bp) [2]. It could be explained by that fact that larger fragments had higher amount of negative charge, facilitating the interaction with sperm membrane. Moreover, we use flow cytometry to detect exogenous DNA internalized by sperm cells. Silva et al., using fluorescence in situ hybridization (FISH) shows a transfection rate following incubation around to $17 \%$ in swine sperm [37]. On the other hand, Canovas et al. detect by flow cytometry around to $29 \%$ of sperm cells carrying exogenous DNA after incubation in bovine sperm [38]. Arias et al. (2018) hypothesize that detection of exogenous DNA by flow cytometry can be 10 times more sensitive than conventional fluorescence microscopy. This fact could explain the differences among different studies that used flow cytometry to evaluate transfection rates on sperm cells.

Kim et al. tested more than 70 cell lines, obtaining transfection rates greater than $50 \%$ in hard-to-transfect cell lines such as primary and stem cells. Sperm cells are considered a hard-to-transfect cell both in mammalian and fish species. 
Here, transfection rate of fish spermatozoa was positively affected for tip type electroporation, increasing the number of cells containing exogenous DNA. In the present study, voltages ranging from 750 to $1500 \mathrm{~V}$ demonstrated significant differences in transfection rates, while the $500 \mathrm{~V}$ the voltage induced minimal cell viability decrease and with the similar results regards transfection rate in comparison to higher voltages. Patil and Khoo [19] demonstrated that cuvette electroporation did not increase the number of transfected sperm, although it increased the rate of transgenic zebrafish. Blödorn et al. demonstrated that capillary tip type electroporation lead transfection rates up to $80 \%$ at $900 \mathrm{~V}$; nonetheless the voltages up to $600 \mathrm{~V}$ reach a transfection rate of $70 \%$ with no detrimental effects observed in cryopreserved bovine cells [11].

It is well known that high voltages increase the transfection rates, however, decrease severely the cell viability and in general cell viability and transfection rates are inversely proportional. Here we demonstrate that zebrafish sperm could be transfected using tip type electroporation with minimum side effects on sperm cells using tip type electroporation. Kim et al. previously demonstrated main reasons to this improvement in transfection rate by tip type electroporation are related to design, physical geometry and electric resistance [10].

In the present study increased electric energy had a negative effect on the total motility and progressive motility of electroporated sperm. At higher voltages (1000, 1250 and $1500 \mathrm{~V})$, the effects on motility were more deleterious. However, at lower voltages (500 and $750 \mathrm{~V}$ ), the tip type electroporation approach had a slight effect on sperm motility. Patil and Khoo [19] demonstrated that cuvette electroporation negatively affects sperm motility and the results found in our study are similar to those presented by them. However, the voltage of $1500 \mathrm{~V}$ in cuvette electroporation reduced sperm motility to $25 \%$ in the zebrafish sperm. In our study, motility was reduced to 53\%. Sin et al. observed that voltages of 625 and $1125 \mathrm{~V}$ in cuvette electroporation reduced the sperm motility to less than $5 \%$ in chinook salmon [39]. Blödorn and colleagues previously observed that electrotransfection resulted in a substantial detrimental effect on bovine sperm motility parameters, even at lowest voltage $(500 \mathrm{~V})$ was observed a reduction of almost $50 \%$ on total sperm motile count. We can attribute these results to the fact that those cells were previously cryopreserved. The capillary electroporation used in the present study, at similar voltages, increase the transfection in sperm of zebrafish with few negative effects on sperm motility. It is well known that ion concentrations $(\mathrm{K}+, \mathrm{Na}+$, and $\mathrm{Ca} 2+)$, osmotic pressure, $\mathrm{pH}$, temperature and medium dilution rate affect fish sperm motility [40]. Cuvette electroporation systems use aluminium electrodes that produce secondary chemical reactions during electric shock releasing ions [41]. Tip type electroporation use electrodes coated with gold that reduce the release of ions during transfection. In addition, the tip type system has a high electrical resistance that in turn produce fewer chemical reactions and in consequence low release of ions [10]. Also, reduced $\mathrm{pH}$ and temperature changes during tip type electroporation in comparison to cuvette system were reported [10]. In this sense, reduced metal and hydrogen ions release and minimal temperature changes during tip type electroporation may explain the slight deleterious effects on sperm motility and motility duration observed at lowest voltages used here.

Parameters such as progressive motility and velocity parameters are strong correlated with fertility ability in bulls. According to sperm motility results, other velocity parameters such as progressive motility and velocity of electroporated sperm cells at low voltages $(500$ and $750 \mathrm{~V})$ were similar to controls. To the best of our knowledge, previous studies with cuvette electroporation on fish sperm has not performed robust CASA analyses such as VCL, VSL, VAP, and STR. It has been previously shown that movement variables such as VAP and VSL are strongly correlated with fertilization rates in Anthocidaris crassispina [42]. These results are in agreement with our previous study in bovine sperm cells using tip type electroporation [11]. In a similar way, at high voltages, there was an increased loss of integrity related to damaged plasma membrane, while at low voltages, cell integrity was slight reduced in comparison to non-electroporated spermatozoa. This is because after reaching a critical value for the electric field, the plasma membrane became irreversibly permeabilized. Consequently, this condition may decrease cell viability [43]. Cell integrity is essentially to maintain fertilization ability. Thus, taken together results of motility, progressive motility, velocity parameters and cell integrity, we suggest that tip type electroporation at low voltages could maintain fertilization rates at similar levels compared to non-electroporated zebrafish sperm, however, further studies must be conducted to elucidate if tip type electroporation can be used without interfering with fertilization rates and improving the generation of transgenic fish.

Mitochondria are essential for providing energy to flagellum and their number and function have been positively correlated with sperm motility and fertilization capacity [44]. Assessment of mitochondrial functionality by measuring mitochondrial membrane potential can be useful as a marker of fish sperm quality [45]. Some stressful procedures can affect sperm motility through two types of damage: direct damage to mitochondrial DNA or alterations to the inner or outer membrane [46]. Our experiments suggest that capillary electroporation does not affect mitochondrial function. These results corroborate with our previous results using tip type electroporation in bovine sperm, in which reduced motility was caused by electroporation conditions rather than loss of mitochondrial functionality [11]. 
Mitochondria are also involved with redox balance and oxidative stress in sperm. In this regard, under stress conditions, the electron transport chain has a major role in the production of a variety of reactive oxygen species (ROS) which exceeds the spermatic limited antioxidant defences. Thus, a state of oxidative stress is induced, characterized by peroxidation of sperm membrane lipids [47, 48]. Relatively little is known regarding the fatty acid composition of zebrafish spermatozoa, however, an increase in ROS has been linked to abnormal or damaged spermatozoa in other species $[49,50]$. The present results demonstrated that ROS concentration were not affected by tip type electroporation, even in high voltages, suggesting that these conditions do not increase oxidative stress.

\section{Conclusion}

In summary, zebrafish sperm was successfully transfected using tip type electroporation, with minimal loss in sperm motility, cell integrity and without effects in progressive motility, velocity parameters, mitochondrial functionality and ROS production at lower voltages, such as $500 \mathrm{~V}$. This tip type electroporation provides a method with minimal harmful effects to introduce exogenous DNA into sperm cells and future studies should be conducted to assess the potential of tip type electroporation in the generation of transgenic zebrafish by SMGT.

Funding This study was supported by the Ministério da Ciência, Tecnologia, Inovações e Comunicações/Conselho Nacional de Desenvolvimento Científico e Tecnológico (Edital Universal \#422292/20168), Fundação de Amparo à pesquisa do Estado do Rio Grande do Sul (FAPERGS-FAPESP \# 19/2551-0002283-2 and FAPERGS PqG \# 17/2551-0000953-3) and Coordenação de Aperfeiçoamento de Pessoal de Nível Superior (AUXPE \#2537/2018). ASVJ, CDC, and VFC are also individually supported by Conselho Nacional de Desenvolvimento Científico e Tecnológico.

\section{Compliance with ethical standards}

Conflict of interests The authors declare that they have no competing interests.

Ethical Approval The methodology used in this study was approved by the Ethics Committee of the Federal University of Pelotas / RS, Brazil, (number 7836).

\section{References}

1. Lavitrano M, Camaioni A, Fazio VM et al (1989) Sperm cells as vectors for introducing foreign DNA into eggs: genetic transformation of mice. Cell 57:717-723. https://doi.org/10.1016/00928674(89)90787-3
2. Lavitrano M, French D, Zani M et al (1992) The interaction between exogenous DNA and sperm cells. Mol Reprod Dev 31:161-169. https://doi.org/10.1002/mrd.1080310302

3. Lavitrano M, Forni M, Bacci ML et al (2003) Sperm mediated gene transfer in pig: selection of donor boars and optimization of DNA uptake. Mol Reprod Dev 64:284-291. https://doi. org/10.1002/mrd.10230

4. Campos VF, de Leon PMM, Komninou ER et al (2011) NanoSMGT: Transgene transmission into bovine embryos using halloysite clay nanotubes or nanopolymer to improve transfection efficiency. Theriogenology 76:1552-1560. https://doi. org/10.1016/j.theriogenology.2011.06.027

5. Lavitrano M, Bacci ML, Forni M et al (2002) Efficient production by sperm-mediated gene transfer of human decay accelerating factor (hDAF) transgenic pigs for xenotransplantation. Proc Natl Acad Sci 99:14230-14235. https://doi.org/10.1073/ pnas.222550299

6. Eghbalsaied S, Ghaedi K, Laible G et al (2013) Exposure to DNA is insufficient for in vitro transgenesis of live bovine sperm and embryos. Reproduction 145:97-108. https://doi. org/10.1530/REP-12-0340

7. Cervia LD, Yuan F (2018) Current progress in electrotransfection as a nonviral method for gene delivery. Mol Pharm 15:3617-3624. https://doi.org/10.1021/acs.molpharmac eut. 8 b00207

8. Zhong J, Wang Y, Zhu Z (2002) Introduction of the human lactoferrin gene into grass carp (Ctenopharyngodon idellus) to increase resistance against GCH virus. Aquaculture 214:93101. https://doi.org/10.1016/S0044-8486(02)00395-2

9. Sin FYT, Walker SP, Symonds JE et al (2000) Electroporation of salmon sperm for gene transfer: efficiency, reliability, and fate of transgene. Mol Reprod Dev 56:285-288. https:// doi.org/10.1002/(SICI)1098-2795(200006)56:2+<285:AIDMRD16>3.0.CO;2-4

10. Kim JA, Cho K, Shin MS et al (2008) A novel electroporation method using a capillary and wire-type electrode. Biosens Bioelectron 23:1353-1360. https://doi.org/10.1016/j.bios.2007.12.009

11. Blödorn EB, Domingues WB, Komninou ER et al (2018) Voltages up to $600 \mathrm{~V}$ did not affect cryopreserved bovine spermatozoa on capillary-type electroporation. Reprod Biol 18:416-421. https:// doi.org/10.1016/j.repbio.2018.09.003

12. Lanes CFC Marins LF (2012) Sperm-mediated gene transfer in aquatic species: present, past and future. In: Sperm-mediated gene transfer: concepts and controversies. Science Publishers, Bentham, pp 64-75. https://doi.org/10.2174/978160805237011 201010064

13. Powers DA, Hereford L, Cole T et al (1992) Electroporation: a method for transferring genes into the gametes of zebrafish (Brachydanio rerio), channel catfish (Ictalurus punctatus), and common carp (Cyprinus carpio). Mol Mar Biol Biotechnol 1:301-308

14. Khoo H-W, Ang L-H, Lim H-B, Wong K-Y (1992) Sperm cells as vectors for introducing foreign DNA into zebrafish. Aquaculture 107:1-19. https://doi.org/10.1016/0044-8486(92)90046-N

15. Campos VF, Amaral MG, Seixas FK et al (2011) Exogenous DNA uptake by South American catfish (Rhamdia quelen) spermatozoa after seminal plasma removal. Anim Reprod Sci 126:136-141. https://doi.org/10.1016/j.anireprosci.2011.05.004

16. Lanes CFC, Sampaio LA, Marins LF (2009) Evaluation of DNase activity in seminal plasma and uptake of exogenous DNA by spermatozoa of the Brazilian flounder Paralichthys orbignyanus. Theriogenology 71:525-533. https://doi.org/10.1016/j.theriogeno logy.2008.08.019

17. Teame T, Zhang Z, Ran C et al (2019) The use of zebrafish (Danio rerio) as biomedical models. Anim Front 9:68-77. https://doi. org/10.1093/af/vfz020 
18. Galindo-Villegas J (2020) The Zebrafish Disease and Drug Screening Model: A Strong Ally Against Covid-19. Front Pharmacol 11:680. https://doi.org/10.3389/fphar.2020.00680

19. Patil JG, Khoo HW (1996) Nuclear internalization of foreign DNA by zebrafish spermatozoa and its enhancement by electroporation. J Exp Zool 274:121-129. https://doi.org/10.1002/(SICI)1097010X(19960201)274:2<121:AID-JEZ5>3.0.CO;2-R

20. Wang L, Li J (2019) 'Artificial spermatid'-mediated genome editing†. Biol Reprod 101:538-548. https://doi.org/10.1093/biolre/ ioz087

21. Konoval O, Korol P, Tabaka P et al (2019) Generation of transgenic ducks by crispr/CAS9-mediated gene inser-tion combined with the sperm-mediated gene transfer (SMGT). Biopolym Cell 35:427-436. https://doi.org/10.7124/bc.000A16

22. Varshney GK, Sood R, Burgess SM (2015) Understanding and editing the zebrafish genome. Adv Genet 92:1-52. https://doi. org/10.1016/bs.adgen.2015.09.002

23. Batista M, Vilar J, Rosario I, Terradas E (2016) Influence of different anaesthetic protocols over the sperm quality on the fresh, chilled $\left(4{ }^{\circ} \mathrm{C}\right)$ and frozen-thawed epididymal sperm samples in domestic dogs. Reprod Domest Anim 51:758-765. https://doi. org/10.1111/rda. 12743

24. Varela Junior AS, Corcini CD, Gheller SMM et al (2012) Use of amides as cryoprotectants in extenders for frozen sperm of tambaqui, Colossoma macropomum. Theriogenology 78:244-251. https://doi.org/10.1016/j.theriogenology.2012.02.029

25. Domingues WB, da Silveira TLR, Komninou ER et al (2017) Flow cytometric sex sorting affects CD4 membrane distribution and binding of exogenous DNA on bovine sperm cells. Zygote 25:519-528. https://doi.org/10.1017/S0967199417000375

26. Sim B-W, Cha J-J, Song B-S et al (2013) Efficient production of transgenic mice by intracytoplasmic injection of streptolysin-Otreated spermatozoa. Mol Reprod Dev 80:233-241. https://doi. org/10.1002/mrd.22158

27. Cavalcanti PV, Milazzotto MP, Simões R et al (2016) Cell viability of bovine spermatozoa subjected to DNA electroporation and DNAse I treatment. Theriogenology 85:1312-1322. https://doi. org/10.1016/j.theriogenology.2015.12.017

28. Wilson-Leedy JG, Ingermann RL (2007) Development of a novel CASA system based on open source software for characterization of zebrafish sperm motility parameters. Theriogenology 67:661672. https://doi.org/10.1016/j.theriogenology.2006.10.003

29. Collares T, Campos VF, Seixas FK et al (2010) Transgene transmission in South American catfish (Rhamdia quelen) larvae by sperm-mediated gene transfer. J Biosci 35:39-47. https://doi. org/10.1007/s12038-010-0006-6

30. Acosta IB, Junior ASV, e Silva EF et al (2016) Effects of exposure to cadmium in sperm cells of zebrafish, Danio rerio. Toxicol Rep 3:696-700. https://doi.org/10.1016/j.toxrep.2016.08.002

31. Petrunkina AM, Volker G, Weitze K-F et al (2005) Detection of cooling-induced membrane changes in the response of boar sperm to capacitating conditions. Theriogenology 63:2278-2299. https ://doi.org/10.1016/j.theriogenology.2004.10.008

32. Piehler E, Petrunkina AM, Ekhlasi-Hundrieser M, Töpfer-Petersen E (2006) Dynamic quantification of the tyrosine phosphorylation of the sperm surface proteins during capacitation. Cytometry A 69A:1062-1070. https://doi.org/10.1002/cyto.a.20338

33. Domínguez-Rebolledo A, Martínez-Pastor F, Bisbal A et al (2011) Response of thawed epidi dymal red deer spermatozoa to increasing concentrations of hydrogen peroxide, and importance of individual male variability: oxidative stress in red deer spermatozoa. Reprod Domest Anim 46:393-403. https://doi.org/10.1 111/j.1439-0531.2010.01677.x

34. Fernández-Gago R, Domínguez JC, Martínez-Pastor F (2013) Seminal plasma applied post-thawing affects boar sperm physiology: a flow cytometry study. Theriogenology 80:400-410. https ://doi.org/10.1016/j.theriogenology.2013.05.003
35. Fernandes Silva E, Varela AS, Cardoso TF et al (2016) Reproductive toxicology of 2,4 dinitrophenol in boar sperm. Toxicol In Vitro 35:31-35. https://doi.org/10.1016/j.tiv.2016.05.002

36. Anzar M, Buhr MM (2006) Spontaneous uptake of exogenous DNA by bull spermatozoa. Theriogenology 65:683-690. https:// doi.org/10.1016/j.theriogenology.2005.06.009

37. da Silva Z, de Souza AP, Pandolfi JRC et al (2018) Comparison between electroporation and polyfection in pig sperm: efficiency and cell viability implications. Zygote 26:286-293. https://doi. org/10.1017/S0967199418000205

38. Canovas S, Gutierrez-Adan A, Gadea J (2010) Effect of exogenous DNA on bovine sperm functionality using the sperm mediated gene transfer (SMGT) technique. Mol Reprod Dev 77:687-698. https://doi.org/10.1002/mrd.21205

39. Sin FYT, Bartleya AL, Walker SP, et al (1993) Gene transfer in chinook salmon (Oncorhynchus tshawytscha) by electroporating sperm in the presence of pRSV-1acZ DNA. Aquaculture 117:5769. https://doi.org/10.1016/0044-8486(93)90123-G

40. Alavi S, Cosson J (2006) Sperm motility in fishes. (II) Effects of ions and osmolality: a review. Cell Biol Int 30:1-14. https://doi. org/10.1016/j.cellbi.2005.06.004

41. Loomis-Husselbee JW, Cullen PJ, Irvine RF, Dawson AP (1991) Electroporation can cause artefacts due to solubilization of cations from the electrode plates. Aluminum ions enhance conversion of inositol 1,3,4,5-tetrakisphosphate into inositol 1,4,5-trisphosphate in electroporated L1210 cells. Biochem J 277:883-885. https:// doi.org/10.1042/bj2770883

42. Au DWT, Reunov AA, Wu RSS (2001) Reproductive impairment of sea urchin upon chronic exposure to cadmium. Part II: effects on sperm development. Environ Pollut 111:11-20. https://doi. org/10.1016/S0269-7491(00)00036-1

43. Rosazza C, Haberl Meglic S, Zumbusch A et al (2016) Gene electrotransfer: a mechanistic perspective. Curr Gene Ther 16:98-129. https://doi.org/10.2174/1566523216666160331130040

44. Ferramosca A, Pinto Provenzano S, Montagna DD et al (2013) Oxidative stress negatively affects human sperm mitochondrial respiration. Urology 82:78-83. https://doi.org/10.1016/j.urolo gy.2013.03.058

45. Ulloa-Rodríguez P, Figueroa E, Díaz R et al (2017) Mitochondria in teleost spermatozoa. Mitochondrion 34:49-55. https://doi. org/10.1016/j.mito.2017.01.001

46. Figueroa E, Valdebenito I, Farias JG (2016) Technologies used in the study of sperm function in cryopreserved fish spermatozoa. Aquac Res 47:1691-1705. https://doi.org/10.1111/are.12630

47. Aitken RJ, De Iuliis GN (2010) On the possible origins of DNA damage in human spermatozoa. Mol Hum Reprod 16:3-13. https ://doi.org/10.1093/molehr/gap059

48. De Iuliis GN, Thomson LK, Mitchell LA et al (2009) DNA damage in human spermatozoa is highly correlated with the efficiency of chromatin remodeling and the formation of 8-hydroxy2 '-deoxyguanosine, a marker of oxidative stress 1. Biol Reprod 81:517-524. https://doi.org/10.1095/biolreprod.109.076836

49. Aitken RJ, Clarkson JS, Hargreave TB et al (1989) Analysis of the relationship between defective sperm function and the generation of reactive oxygen species in cases of oligozoospermia. J Androl 10:214-220. https://doi.org/10.1002/j.1939-4640.1989.tb00091.x

50. Rao B, Soufir JC, Martin M, David G (1989) Lipid peroxidation in human spermatozoa as relatd to midpiece abnormalities and motility. Gamete Res 24:127-134. https://doi.org/10.1002/mrd.11202 40202

Publisher's Note Springer Nature remains neutral with regard to jurisdictional claims in published maps and institutional affiliations. 